\title{
Investigation of Mechanical Properties of Plastic Bottle Brick
}

\author{
Sanuar Ahmed Saikat*, Md. Golam Gaffar Khan, H Golam Morshed
}

Department of CE, AUST, Dhaka, Bangladesh

\author{
DOI: $10.36348 /$ sjeat.2019.v04i11.002 | Received: 21.10.2019| Accepted: 28.10 .2019 | Published: 20.11 .2019 \\ *Corresponding author: Sanuar Ahmed Saikat
}

\section{Abstract}

Introduction: Cement and bricks manufacturing process will contribute to a high emission carbon- dioxide (CO2) that may lead to global warming. The alternative way thatcan solve the problem is replacing by the use of bricks in construction by plastic bottles filled with sand, mortar and other types of materials. Objective: The purpose of this study is to examine the possibility of using plastic bottles in concrete block. The plastic bottles are used to reduce the cost, Environmental effects and the usage of concrete in the masonry units. Method: Concrete is placed around each bottle to encase it in the masonry units. The study utilizes $500-\mathrm{mL}$ plastic bottles filled with soil and cement mortar placed inside concrete masonry units and analyzing the compressive strength. The testing for compressive strength was determined according to the ASTM C140 standard. Result: This study shows Soil Brick Block and Mortar Brick Block has a similar average compressive strength of $4.6 \mathrm{~N} / \mathrm{mm}^{2}$ and $4.4 \mathrm{~N} / \mathrm{mm}^{2}$. This abruptly high compressive strength of soil brick block is found due to the 'Confinement Effect' shown by the plastic bottle. Thus the use of concrete can be reduced, introducing the soil bottle brick in concrete masonry. Conclusion: Further research on the other properties, economics and environmental benefits can be conducted to confirm the practice of using water bottles inside concrete blocks. And this study recommends the Soil Brick Block can be used in footpath, river banks and other such structures where only high compressive strength is necessary.

Keywords: Mechanical Properties, Plastic Bottle Bricks, Confinement Effect.

Copyright @ 2019: This is an open-access article distributed under the terms of the Creative Commons Attribution license which permits unrestricted use, distribution, and reproduction in any medium for non-commercial use (NonCommercial, or CC-BY-NC) provided the original author and source are credited.

\section{INTRODUCTION}

At the present time, the likelihood of developing the renewable resources such as solar, wind, geothermal has been delivered for us more than before, and progress of this science is making progress. But those energies can be selected as one of the renewable and substitute energies instead of fossil fuels which are economical as possible and have fewer environmental impacts [1].

"Global warming" as a term, refers to what is believed to be a trend where earth's temperature is increasing. This is assumed to be mainly due to the emission of man-made pollutants and ecological disturbances that cause more of the sun's energy to be trapped within the atmosphere. These pollutants are referred to as-so called greenhouse gases [2]. Maximum pollutant occur man made in the environment in some way or another and while naturally, pollution is also significant compared to that man-made occurring, they may affecting the natural balance in the environment. It is assumed that it would take many years for there to be catastrophic consequences to the increase in Green
House gas emissions. Recycling or reuse of plastic can reduce the pollution in consequence of global warming.

Eco-house also knew as Green building, is the creative buildings and supportive infrastructure that reduce the use of resources, create healthier living environments for people, and minimize negative impacts on local, regional, and global ecosystems [3].

The strength of bottle bricks has been doubted by the public since they are made from plastic bottles. However, this doubt is solved because bottle bricks are stronger than common bricks and they are bullet proof [3]. In a small village in Nigeria, a solution has been applied to not only provide shelter in a poverty-stricken country but find a use for the refuse [4]. 


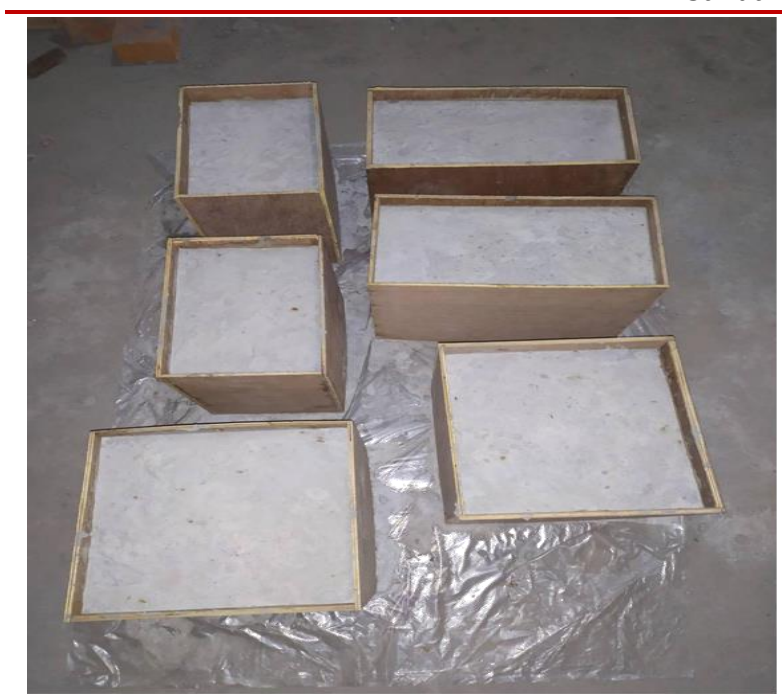

Fig-1: Prepared Bottle Brick Blocks

If we look further into the cause of this problem; it can be noted that cost of construction, materials, land, and transportation are some of the main factors leading to increasing in housing unaffordability. Use of locally available materials like plastic bottle brick, low-quality components, and utilization of waste in construction are some of the reliable solutions for low-cost housing, particularly for poor people. For a sustainable housing for urban poor households and rural households, utilization of plastic bottle construction has been explored from different sources and their potential.

This research has been based on two main concerns. The first is to flourish the problem with plastic bottle environmental issues. Hence it is important to find an alternative way of disposing of these wastes to save the environment. The second important issue is the cost of construction of bricks because most of the poor urban or rural people can't afford to build their houses with highly costly bricks. In Bangladesh, it is quite tough for the poor people to build their own house costly construction material like bricks.

\section{OBJECTIVES}

\section{General Objective}

The main objective of this study is to investigate the mechanical properties of plastic bottle brick.

\section{Specific Objectives}

- To investigate the mechanical (strength) behavior of the plastic bottle brick

- To test and compare the compressive strength of brick bottle with a brick.

- To make a green structure to conserve natural resources for future need

- To make sure less environment pollution due to increasing plastic bottle around the globe.

- To make economical construction for lowincome people

\section{METHODOLOGY}

Our research intends to investigate the application of waste plastic bottles as one of the urban wastage in buildings construction and that how it can lead to sustainable development. In this research, we have tried to use different types of construction of plastic bottle masonry and compare various factors like as compressive strength, durability and construction cost with normal brick masonry.

This proves the necessity for research regarding the amount of cement and properties of Plastic Bottle Bricks as well as other technical and nontechnical aspects to determine the appropriate mix design ratio of cement, sand, water, and feasibility in the construction.

Here, we have made basically two types of. Bottle Brick Sand filled bottle brick and Mortar filled Bottle Brick. Sand: Cement ratio was 6: 1 and water is used $50 \%$ of thecement. Low ratio of the cement has used to make the Brick Bottle economical and at the same time to ensure having high compressive strength.

\section{Material Collection}

We collected the waste plastic bottles of 500 $\mathrm{ml}$ from local plastic dumping site somewhere in Tejgaon industrial area. In order to collect the bottles we asked the local worker to gather the same type and same size bottles. We collected near above 70 PET bottles from that dumping site. Necessary directions were given to them by us. Other necessary materials like soil, sand, cement and tamping rod were collected. Wooden frame were also be prepared by local carpenter. And soil collected from a construction site in Tejgaon industrial area.

\section{Categorization of Samples}

Six numbers of Blocks sample were prepared for determining compressive load. As mentioned previously, Here, we made basically two types of blocks.

Category A: Soil filled bottle brick blocks (AS)

- Type: AS1 (12" X 12"), L/B ratio is 1

- Type: AS2 (12" X 8"), L/B ratio is 1.5

- Type: AS3 (16" X 8"),L/B ratio is 2

Category B: Mortar filled bottle blocks (BS)

- Type: BS1 (12" X 12"), L/B ratio is 1

- Type: BS2 (12" X 8"), L/B ratio is 1.5

- Type: BS3 (16" X 8"),L/B ratio is 2

\section{Test Procedure}

\section{Procedure of Compressive Strength Test on Bottle Bricks}

- The specimens are placed with flat faces horizontally both soil and mortar filled brick bottle between plates of the testing machine. 
- The compressive load is applied axially at a uniform rate and noted maximum load at failure which is the ultimate load.

- The specimens are failed at the maximum load and no further increase of load is applied the testing machine.

\section{Procedure of Compressive Strength Test on Blocks}

- The specimens (blocks) are placed with vertical alignment between plane plates of the UTM (machine).

- The compressive load is applied vertically along the specimen at a uniform rate and noted maximum load at failure which is the ultimate load.

- The specimens are failed at the ultimate load and no further increase of load is applied on the UTM (machine).

\section{Analytical Methods}

\begin{tabular}{|c|c|c|c|}
\hline Category & Sample & Compressive Load (N) & Compressive Average Load (N) \\
\hline \multirow[t]{3}{*}{ A (Soil Brick) } & A1 & 251300 & \multirow{3}{*}{250334} \\
\hline & A2 & 235400 & \\
\hline & $\mathrm{A} 3$ & 264300 & \\
\hline \multirow[t]{3}{*}{ B (Mortar Brick) } & B1 & 551100 & \multirow[t]{3}{*}{555034} \\
\hline & B2 & 567300 & \\
\hline & B3 & 546700 & \\
\hline
\end{tabular}

Figure-2 shows the compressive stress of the two types of bottle bricks, for category-A (soil), it is 21.4 and for category-B (Mortar), it is 47.4 .

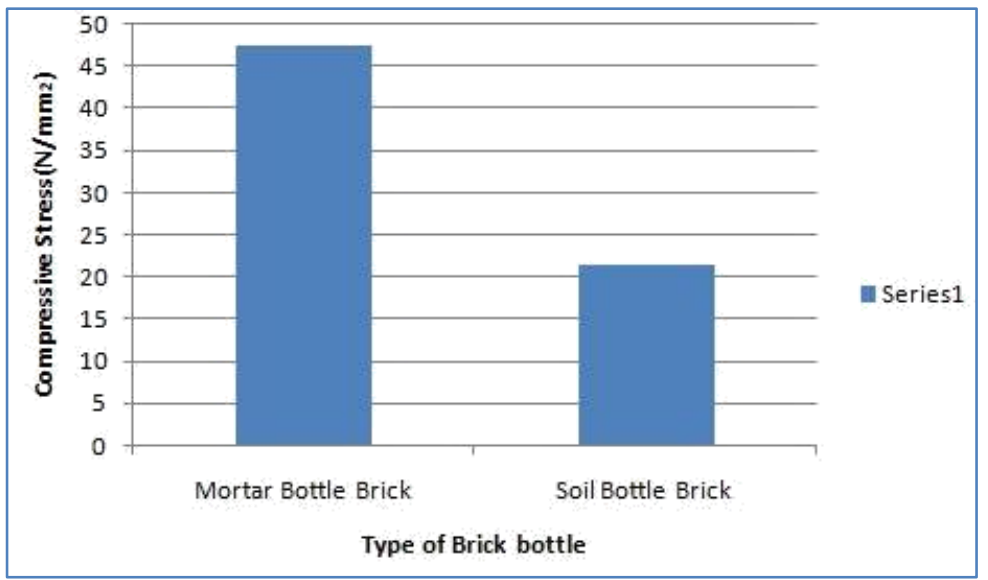

Fig-2: Compressive Stress of different types of Bricks

Table-2 and Figure-3 details the compressive stress of soil brick variation with different L/B ratio.

Table-2: Compressive Stress of Soil Brick Block Variation with Different (L/B) Ratio

\begin{tabular}{|l|l|l|l|l|}
\hline Type & L/B ratio & Compressive Load $(\mathbf{N})$ & Area $\left(\mathbf{m m}^{\mathbf{2}}\right)$ & Compressive Stress $\left(\mathbf{N} / \mathbf{m m}^{2}\right)$ \\
\hline AS1 Type & 1 & 350452 & 92903 & 3.77 \\
\hline AS2 Type & 1.5 & 292846 & 61935.36 & 4.72 \\
\hline AS3 Type & 2 & 452369 & 82580.48 & 5.47 \\
\hline
\end{tabular}




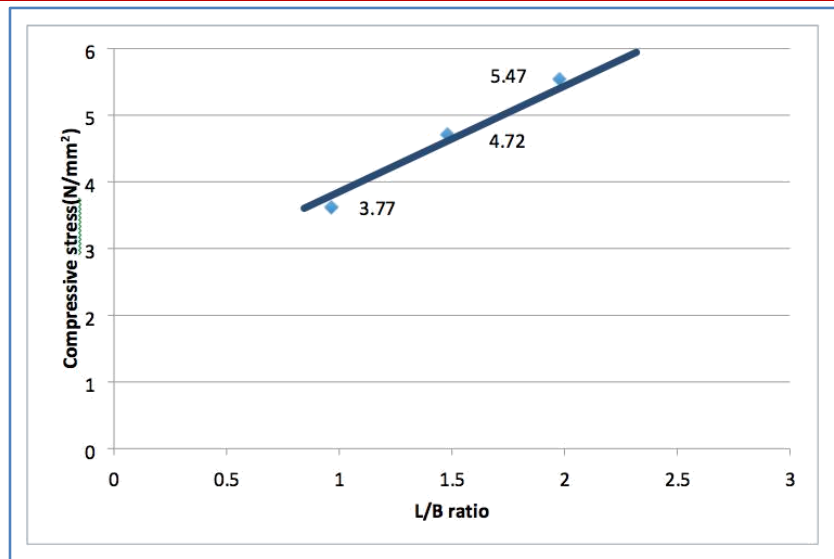

Fig-3: Compressive Stress Varies with Different (L/B) Ratio of Soil Brick Blocks

Table-3 and Figure-4 details the compressive stress of Mortar brick variation with different L/B ratio.

Table-3:

\begin{tabular}{|l|l|l|l|l|}
\hline Type & L/B Ratio & Compressive Load $(\mathbf{N})$ & Area $\left(\mathbf{m m}^{\mathbf{2}}\right)$ & Compressive Stress $\left(\mathbf{N} / \mathbf{m m}^{2}\right)$ \\
\hline BS1 Type & 1 & 320443 & 92903 & 3.44 \\
\hline BS2 Type & 1.5 & 272849 & 61935.36 & 4.40 \\
\hline BS3 Type & 2 & 442368 & 82580.48 & 5.35 \\
\hline
\end{tabular}

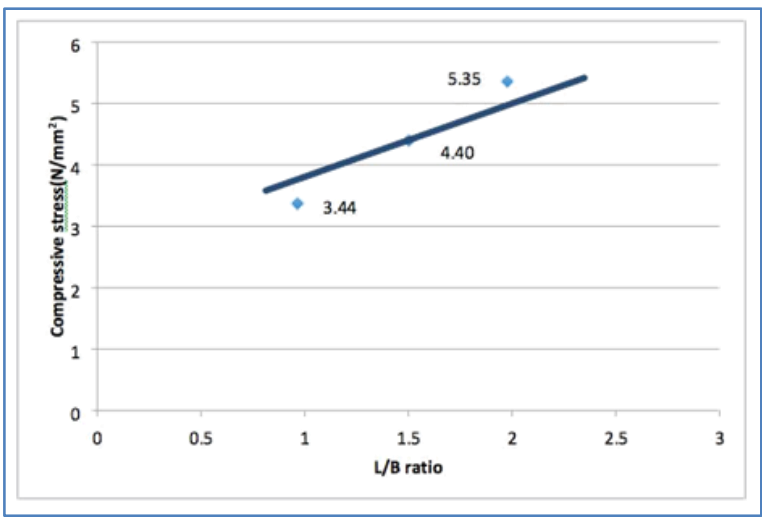

Fig-4: Compressive stress varies with different $(\mathrm{L} / \mathrm{B})$ ratio of Mortar Brick Blocks

Figure-5 shows the compressive stress of the category-A (soil), and category-B (Mortar) blocks.

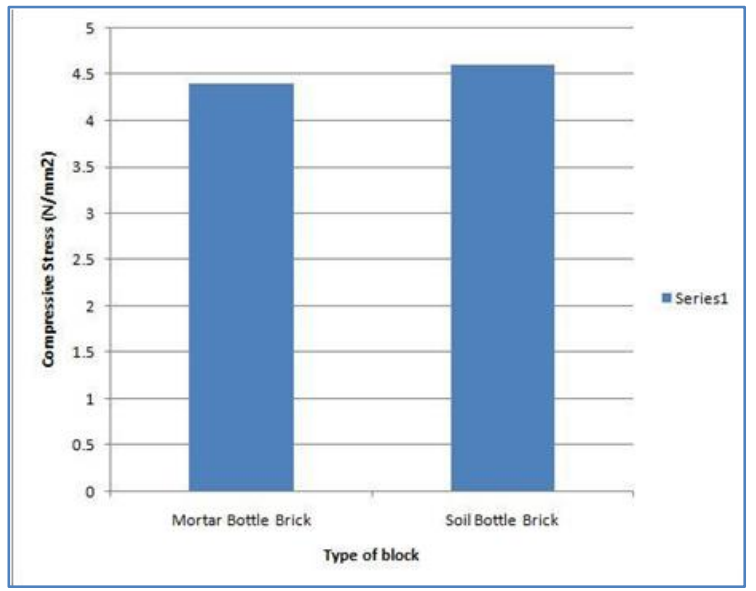

Fig-5: Compressive Stress of Different Types of Blocks

\section{DISCUSSION}

We observed that the compressive stress varies with different types of brick bottles. The compressive stress depends on the material components of the brick bottles. The maximum value of the compressive stress of the bottle brick is $47.4 \mathrm{~N} / \mathrm{mm}^{2}$. Curing is applied to maintain the optimum moisture content (OMC), which isnecessary for hydration of cement to avoid shrinkage crack and premature stressing. The soil filled brick bottle gives less compressive stress than the mortar filled brick bottle. The soil filled brick bottles' compressive stress depends on soil property and compaction inside of the brick bottle. Plastic property is also an important factor for the brick bottle. From these tests, we estimate the relationship of different types of plastic brick bottles and their compressive stresses. It was observed that compressive stresses caused deformations that were increasing as the acting force increased. The bottles were cracking at a very high compressive strength due to inherent ductility of plastic bottle.

With the addition of the normal stresses, while the compressive stresses tended to increase and at the ultimate compressive stresses, the mortar filled brick bottle cracked. For L/B ratio we prepared three types of soil brick bottle where L/B ratio was usually $1,1.5$ and 2 . We found three values of compressive stresses. When $\mathrm{L} / \mathrm{B}$ ratio is 1 we found compressive stress value 3.77 $\mathrm{N} / \mathrm{mm}^{2}$. Similarly whenL/B ratio increased to $\mathrm{L} / \mathrm{B}$ ratio $=1.5$ the value of compressive stress is $4.72 \mathrm{~N} / \mathrm{mm}^{2}$ and when L/B ratio is 2 we found the compressive stress value, which is $5.47 \mathrm{~N} / \mathrm{mm}^{2}$. We observed that the compressive stress is high for the high slenderness ratio. On the other hand, we also observed that when $\mathrm{L} / \mathrm{B}$ ratio is increasing the compressive stress of the 
block is increasing. For the small slenderness ratio the block behaves like a short column. It is less possibility for the crushing. The compressive stress for the small slenderness ratio $(\mathrm{L} / \mathrm{B})$ is higher than the large slenderness ratio $(\mathrm{L} / \mathrm{B})$.

The bottles block specimen tested without lateral support failed due to bond failure. However, the bottles block specimen built with vertical support demonstrateda large resistance against shear failure. While they revealed very small elastic deformation, the compressive forces tended to give more strength to the masonry as the load increased. As the crashed of the block, we observed that the bottle bricks inside the blocks were also crashed. It was observed in both the soil and mortar filled bottle bricks. It is also notable fromthe bonding between cement mortar and plastic bottle bricks are slightlyweaker than standard bricks.

We got that the compressive stress of soil brick, Mortar brick $4.6 \mathrm{~N} / \mathrm{mm}^{2}, 4.4 \mathrm{~N} / \mathrm{mm}^{2}$. The highest compressive stress value is for soil brick bottle block. As the 10 days curing bottle bricks gave the maximum compressive stress, the block also gave the maximum stress. It is to be noted that all the blocks were used the same mortar ratio (cement: sand $=1: 3$ and water is 50 $\%$ of cement) and the curing of the blocks was performed 28 days equally for three types of blocks as mentioned (Figure-4). Hence, the mortar mixing ratio and the curing was the same for every type of blocks so it might be the only reason for different compressive stresses of blocks using the different types of bricks (soil bottle brick, mortar bottle brick). As we got earlier, soil brick, mortar brick bottles successively gave the compressive stress and so as for the blocks.

Associate professor of the architecture department of Bangladesh University of Engineering and Technology (BUET) said, "There are many examples of building bottle houses in the world. This is the first time I came to know that one has been built in Bangladesh." "It's undoubtedly an environment-friendly creation [5]. Arthur Huang processed 1.8 million used plastic bottles into honeycomb-shaped 'bricks' for a boat-shaped exhibition hall called the Eco-ARK. Built for Taipei's flower show, Eco-ARK has constructed for just one-third the cost of a conventional structure. Once locked together, the bricks are extremely strong [6].

\section{CONCLUSION}

So from this result, it is recommended the (AS3 type) Soil filled bottle block can be used in lieu of Mortar filled bottle block. As it reduces the percentage of use of concrete, perhaps it also reduces the cost. However, this technique still needs some modification for a better result. For example, the using the aggregates may increase the efficiency of composite plastic concrete masonry. And further strength can be gained by perforating the plastic bottle bricks. It is to gain better bonding between plastic bottle and outer cement mortar. There is also a possibility in using hollow bottle in concrete block if lighter structure is necessary.

Further research on the other properties, economics and environmental benefits can be conducted to confirm the practice of using water bottles inside concrete blocks. And this study recommends the Soil Brick Block can be used in footpath, river banks and other such structures where only high compressive strength is necessary.

\section{REFERENCES}

1. Tavakoli-Nabavi, S. E. (2005). Offering innovative building materials with sustainableapplications. In First International Conference style buildings, Iran.

2. Walker, M. G., Mateo, M., Olszewski, E. W., Gnedin, O. Y., Wang, X., Sen, B., \& Woodroofe, M. (2007). Velocity dispersion profiles of seven dwarf spheroidal galaxies. The Astrophysical Journal Letters, 667(1), L53.

3. Gooding, E. R. (1975). Hand gun bullet proof face shield. Google Patents.

4. Pati, F., Jang, J., Ha, D. H., Kim, S. W., Rhie, J. W., Shim, J. H., ... \& Cho, D. W. (2014). Printing three-dimensional tissue analogues with decellularized extracellular matrix bioink. Nature communications, 5, 3935.

5. Rab, A. (2017). Made -In Bangladesh House of Bottles, in The Prothom-alo.

6. Patel, P. A., Shah, A., \& Patel, H. (2016). Waste Plastic Bottles Offering InnovativeBuilding Materials with Sustainable Application. International Journal ofInnovative and Emerging Research in Engineering, 3(3): 38-45. 